\title{
Where are You Watching? Patterns of Visual Exploration in the Ultima- tum Game
}

\author{
Daniela Villani*,1, Davide Massaro ${ }^{2}$, Ilaria Castelli², Antonella Marchetti ${ }^{2}$ \\ ${ }^{1}$ Department of Psychology, Università Cattolica del Sacro Cuore, L.go Gemelli 1, 20123, Milano, Italy \\ ${ }^{2}$ Research Unit on Theory of Mind, Department of Psychology, Università Cattolica del Sacro Cuore, L.go Gemelli, 1, \\ 20123 Milano, Italy
}

\begin{abstract}
The study aimed to advance the traditional issue of identifying decision strategy by analyzing the information processing in terms of visual exploration patterns. Twenty-seven participants played as responders in a computerized version of Ultimatum Game with an anonymous virtual partner.

Responders tended to reject unfair offers, probably due to their taste for fairness and to the unidentifiability of the other player that reduced the willingness to cooperate. Furthermore, according to the evolutionary approach, participants focused their attention more at themselves than at the partner. Among the three type of offers - hyperfair, fair and unfair mid-value offers, such as fair ones, required more number of fixations and fixations duration, related to the more complex cognitive and reasoning processes involved.

Implications of this study could be applied in decisional settings with anonymous partners, such as those online, with future studies confirming the results found and integrating them through other process tracing methodologies.
\end{abstract}

Keywords: Decision-Making, Eye Tracker, Fairness, Reciprocity, Ultimatum Game, Visual Patterns.

\section{INTRODUCTION}

The understanding of human decision-making is a fascinating and challenging issue requiring the contribute of several disciplines, such as economics, psychology and neuroscience [1]. The economic perspective grounds on the classical theory of decision-making, assuming that people should behave rationally, maximizing gains and minimizing losses [2]. According to this view, economists have developed detailed theoretical models for dealing with many decision situations that have the virtue of being formally explicit and that aim to make quantitatively precise predictions about decision-making in a wide range of circumstances.

However, psychological research on judgment and decision-making has experimentally shown that these models do not provide a complete and satisfactory description of human behavior [3]. In particular, as strongly supported by recent findings from neuroeconomics, decision-making, as other human behaviors, has to be viewed not as the product of a single process, but rather as the result of the interaction of different specialized subsystems $[1,4,5]$. According to this perspective and referring to the well-known distinction between automatic and controlled processes [6,7], recently researchers have provided evidence for two systems,

Address correspondence to this author at the Department of Psychology, Università Cattolica del Sacro Cuore, L.go Gemelli 1, 20123, Milano, Italy; Tel: 00390272342585; Fax: 00390272342280;

E-mail: daniela.villani@unicatt.it competing for control in inference making and action: the instinctive affective system - System 1 - and the controlled deliberative system - System 2 [8-11]. System 1 is automatic parallel, affectively charged, it employs heuristic-based processes and it includes fast and instinctive processes formed by associative learning methods that operate largely beyond awareness. On the other hand, System 2 is controlled, rule-based, slow, serial, deliberative and it is constrained by working memory capacity. Furthermore, if the operations involved in controlled processes are often accessible to introspective and explicit description, those involved in automatic processes are usually much less so.

Among methodologies used to identify decisions strategy, eye tracking plays an important role. This methodology has been traditionally adopted by psychological researchers following the eye-mind assumption [12, 13] to record eye movements considered as immediate cues to attention and cognitive process. Although few years ago the application of eye movements to infer decision strategies has not been popular, probably due to its high costs and poor performance, today advances in eye tracking technology have allowed for precise analysis of the temporal information contained in the eye movement record [14]. Eye movements are fast and natural and the application of the eye tracker in the decision-making research lies on the assumption that, where participants are allowed to freely explore the decision information, they sample information by considering several aspects of the interpersonal relationships management, among which reciprocity, by directing their gaze to them $[15,16]$. 
The increase of eye tracking application to decision making analysis [16] has led to the development of several models aimed to describe the eyes' behavior during the information processing [17-20]. Two leading models are those of Shimojo and colleagues [17, 19, 21] and of Russo and Leclerc [20]. Shimojo and colleagues [17, 19, 21] formulated the Gaze Cascade Model by focusing on two component processes related to looking behavior that interact during preference decisions. The first process is preferential looking, where the person tends to look longer at the stimulus that he/she likes. The second process is the mere exposure effect, where merely looking at a stimulus increases preference for that stimulus [22-25]. Russo and Leclerc [20] identified two stages of processing more focused on attentive and evaluative components: in particular, initial looks reflected orientation and screening functions and additional looks reflected more evaluative processes.

The goal of this study is to analyze the information processing during a decision task typically employed to explore decision making behavior, the Ultimatum Game - UG [26]. In this game, two players have to split a sum of money. One person acts as proposer, who suggests how the money should be divided between the players. The second person plays as responder and has to decide whether to accept or reject the offer. If the responder accepts the offer, the sum is divided as proposed. If the responder rejects the offer, neither participant receives anything.

Whereas standard economic models would predict that proposer should make the smallest possible offer to maximize his/her gain and responder should accept all non-zero offers actually players violate this economic assumption [5, $27,28]$. A common explanation of this discrepancy is that the responders' rejection expresses their "taste for fairness" and that therefore they rather forgo some money than being treated unfairly [29-33]. Besides the taste for fairness, other factors have been claimed to explain such a discrepancy: among the most studied, physical appearance [34], intentionality [35-37], mentalizing [38, 39], morality [40], social roles $[41,42]$ and framing effects related to different types of descriptions of the proposer [33].

To control these confounding variables, we proposed anonymous and unidentifiable proposers [43], which corresponds to those conditions where people cannot identify personal details concerning their partners. ses:

Specifically, we aimed at testing two principal hypothe-

1. There are relationships between the visual information processing patterns and the decision making outcomes (acceptance vs rejection).

2. There are differences between the visual information processing patterns related to the fairness of the offers and those related to the players.

\section{MATERIALS AND METHODOLOGY}

\section{Participants}

Thirty female undergraduate students from the Università Cattolica del Sacro Cuore in Milano (age range 19-22 years) participated in this study. All subjects were healthy and had normal or corrected-to-normal vision.

We excluded participants that were Psychology or Economy students for their familiarity with the decisional constructs, or that had previously taken part in an Ultimatum Game.

Participants with missing data were deleted from the analyses, resulting in a total of 27 participants.

\section{Procedure and Task}

Participants were seated in front of the computer and an initial calibration pattern was displayed to them before running the eye-tracker (Tobii Eye-Tracker X120) session. After having signed an informed consent form and received written instructions, participants performed the task that consisted of a computerized version of the Ultimatum Game where proposers were anonymous and participants played as responders.

The rule of the game has been explained to participants; the sum to be splitted was 10 euro. Participants were also informed that at the end of the game their acceptance rates would have been converted in a shopping voucher with the maximum value of 10 euro.

Nine offer conditions (9-1, 8-2, 7-3, 6-4, 5-5, 4-6, 3-7, 2$8,1-9)$ were presented in a randomized order. Each offer was repeated 4 times with the order of the players counterbalanced (see Fig. 1), yielding a total of 36 trials. These manipulations were adopted to ensure that the participant would
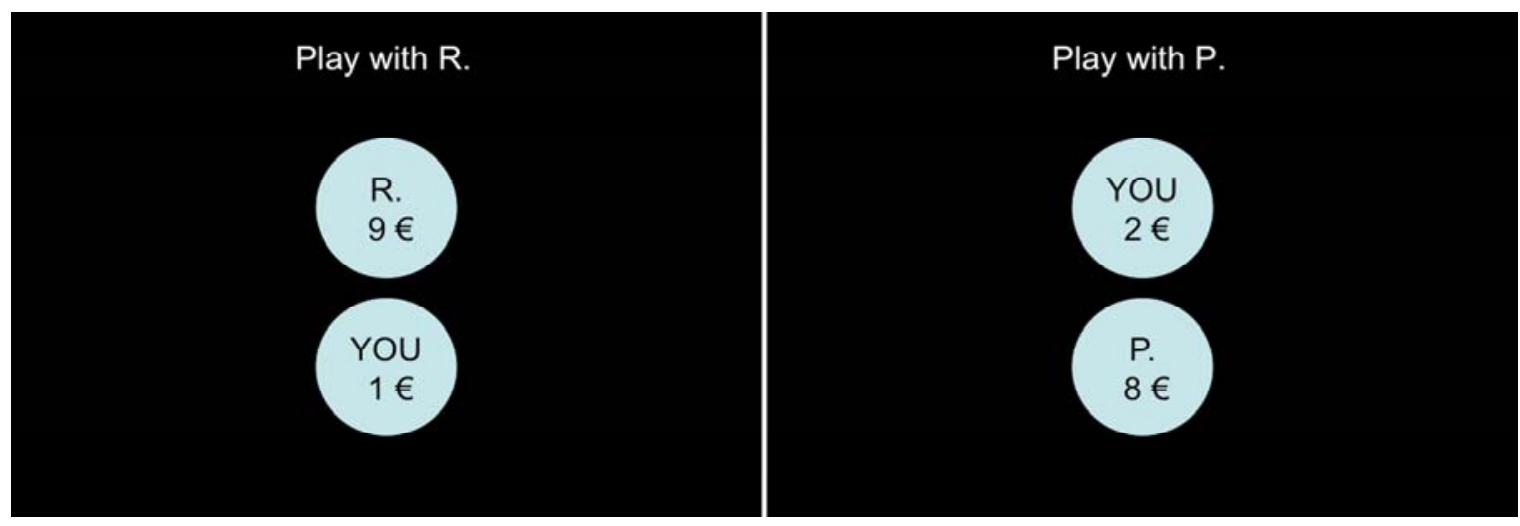

Fig. (1). Two examples of offers where the order of the players was counterbalanced. 
not form any kind of response bias derived from locationbased information about the offers.

The offer was shown for an interval of 7000ms (phase 1), then a white cross on the centre of the screen against a blank background was presented for 2000ms (phase 2). Responders' decisions were communicated orally. In this way we controlled the two decision making phases: the decisional process (eye movements, phase 1) and the choice (behavioral outcomes, phase 2). Analysis was based on the trials representing "unfair" (9-1, 8-2, 7-3,), "fair" (6-4, 5-5, 4-6) and "hyperfair” (3-7, 2-8, 1-9) offers.

Each Eye-tracker registration session lasted approximately 10 minutes.

\section{MEASURES}

\section{Decision Making Outcomes}

At the moment of presentation of the white cross on the centre of the screen against a blank background (phase 2), responders communicated orally their decisions, related to offer acceptation or rejection, by saying "yes" or "no". The experimenter registered responders' decision by filling in an appropriate table. If the offer was accepted, the sum was divided as proposed. If the offer was rejected, none of the participants received anything.

\section{Eye-Tracking Data Acquisition and Model Analysis}

The categories responsible for drawing attention to specific Regions of Interest - ROI (salient regions of an image) were the amount of money received by each player (Self, i.e. the responder, and Other, i.e. the proposer) and the entity of the offer (Unfair, Fair and Hyperfair).

Eye-movement indicators have been processed in terms of number and duration of fixations. Fixations referred to the positioning of a target of interest on the fovea for a variable period of time.
On the one hand, according to authors claiming that exploratory visual behaviour reflects in longer looks at the attractive objects [44] and to the exposure effect, such as the fact that merely looking at a stimulus increases preference for that stimulus [19, 22-25], we considered fixations duration as indicator of interest and preference towards the object. On the other hand, according to Russo and Leclerc [20] stating that initial looks reflected orientation and screening functions and additional looks reflected more evaluative processes, we considered fixations number as indicator of the cognitive evaluation during the decision.

\section{RESULTS}

\section{Decision Making Outcomes and Relationship with Visual Information Processing}

The acceptance was significantly different $[\mathrm{F}(2,25)=$ 79.545, $\mathrm{p}<.001)$ among the three offer's conditions: hyperfair and fair offers were accepted more than unfair ones (respectively, $\mathrm{p}<.001$ and $\mathrm{p}<.001$ ) (Fig. 2).

According to the first hypothesis, we found only a positive correlation between the acceptance of unfair offers and fixations duration on the ROI of the Other (Spearman's Rho Coefficient $=.430, \mathrm{p}<.05$ ).

\section{Visual Information Processing Behavior Related to Fair- ness and Player}

A 2x3 ANOVA was performed to test the second hypothesis and we found main effects related to both the player and the offers' entity. Responders directed and maintained their gaze to themselves. As shown in Table 1, both Fixations duration and Fixations number were significantly higher towards the ROI of Self than the ROI of Other.

Furthermore, responders looked significantly more fair than unfair offers in terms of fixations duration $[\mathrm{M}=26.42$ vs $\mathrm{M}=24.82, \mathrm{~F}(2,25)=4.316, \mathrm{p}<.05]$ and more fair than hyperfair offers $[M=51.33$ vs $M=47.80, F(2,25)=4.318, p<.05)$ in terms of fixations number.

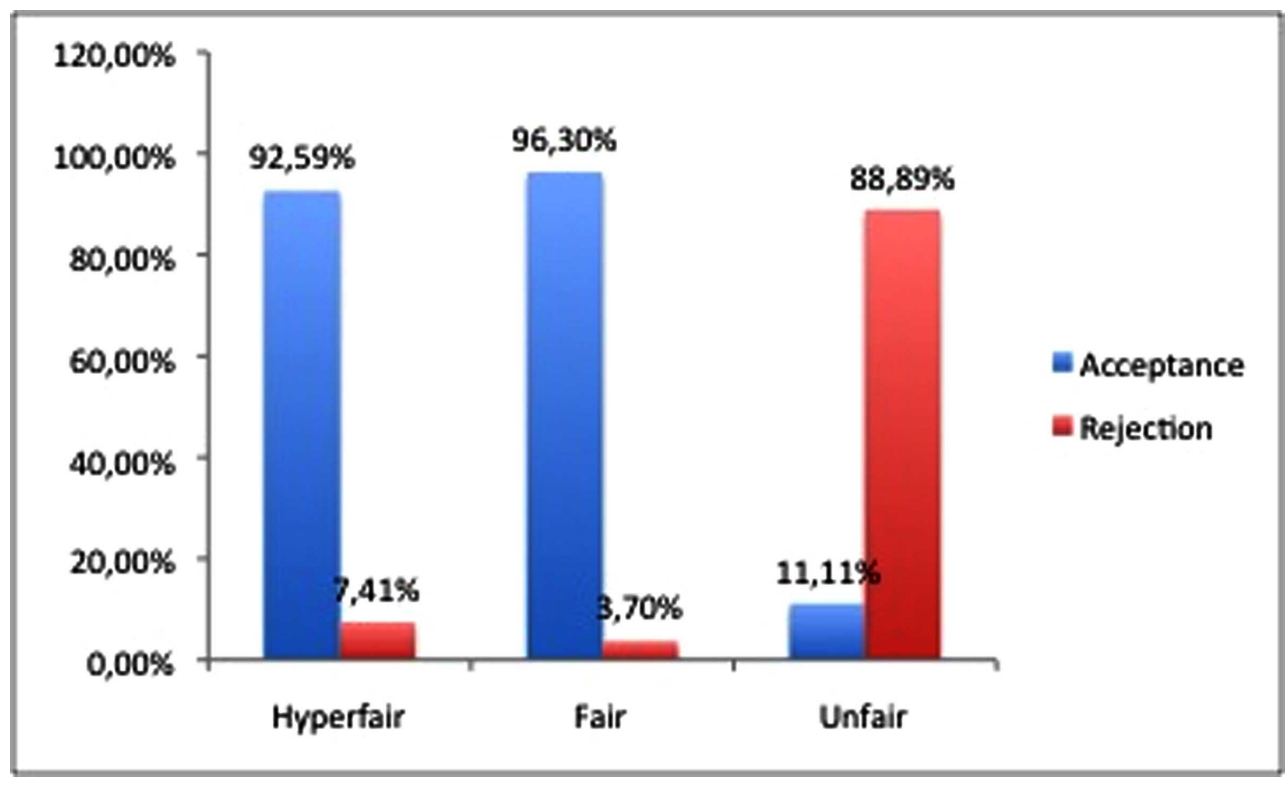

Fig. (2). Ratings of acceptance and rejection related to offer's conditions. 
Table 1. Main Effects of Players

\begin{tabular}{|c|c|c|c|c|c|}
\hline Eye Movement Indicator & Self & Other & df & F & p \\
\hline \hline Fixations duration & $\mathrm{M}=29.43$ & $\mathrm{M}=21.75$ & 1 & $\mathrm{~F}=18.267$ & $\mathrm{p}<.001$ \\
\hline Fixations number & $\mathrm{M}=54.06$ & $\mathrm{M}=44.73$ & 1 & $\mathrm{~F}=15.805$ & $\mathrm{p}<.001$ \\
\hline
\end{tabular}

We found also interaction effects between player and offer's entity for each visual processing indicator. In particular:

- more fixations duration towards the self with fair $(\mathrm{M}=30.02, \mathrm{p}<.005)$ and hyperfair $(\mathrm{M}=30.94, \mathrm{p}<.001)$ than unfair offers $[\mathrm{M}=27.33, \mathrm{~F}(2,25)=13.693]$;

- more fixations number towards the other with fair $(\mathrm{M}=46.89, \mathrm{p}<.05)$ and unfair $(\mathrm{M}=45.23, \mathrm{p}<.05)$ than hyperfair offers $[\mathrm{M}=41.48, \mathrm{~F}(2,25)=6.003]$.

\section{DISCUSSION AND CONCLUSION}

This study aimed to investigate the decision-making process within the context of the Ultimatum Game by analyzing the information processing in terms of visual exploration patterns.

Behavioral outcomes are coherent with the psychological approach to decision-making analysis, because players tend to accept mainly the offers which they judge as fair or hyperfair and to reject offer which they judge as unfair [9]. Literature suggests that the responders' rejection expresses their "taste for fairness" [29-31] and a plausible interpretation is also related to the role played by the unidentifiability of the partner that reduces willingness to cooperate [45, 46].

With respect to the first hypothesis, it was partially supported. We found just a relationship between the pattern of acceptance of unfair offers and fixations duration towards the other. This result is coherent with the exposure effect proposed by Simion and colleagues [19]. Participants made longer looks at the unfair offers and this is associated to an increase of preference for these offers. Probably this is the case of few players that, according to the standard economic theory, accept unfair offers. As suggested by the neuroeconomic approach, strategic interactions between individuals involve an interplay between emotion and deliberation. This interplay has been shown particularly active when participant is confronted with un unfair offer [1] and could have been led responders to direct higher fixations duration towards the other.

With respect to the second hypothesis, as far as players are concerned, we found that responders directed and maintained their gaze more on themselves than on the partner both in terms of number and duration of fixations. A possible explanation of this result could be traced back to the evolutionary approach $[47,48]$. The individual - called to make a decision that can have favourable as well as disadvantageous effects - primarily evaluates his/her potential profit. This is probably just the first step of a complex decisional process, which starts online with an attitude of self-orientation and then evolves in an attempt to reconcile the mere self-interest with the delicate balances of social and relational dynamics (see for example, [49]).

As far as the offers are concerned, participants made longest fixations and highest number of fixations towards fair offers. This result seems to confirm the different roles played by the instinctive- affective system - System 1 - and the controlled - deliberative system - System 2 (8-11). Instinctively, participants spend less fixations duration and less number of fixations on hyperfair and unfair offers, while they look more mid-value offers, such are as the fair ones in this context, that require more complex cognitive and reasoning processes.

Interaction effects also confirmed the activation of the System 1: responders instinctively look more towards themselves when they received fair and hyperfair offers and they look more towards the other when they received fair and unfair offers, perhaps signaling interest and positive emotions towards the self in case of personal advantage and showing that fairness represents the balancing point between the self and the other.

The implications of this study are particularly interesting for decisional settings characterized by the presence of anonymous partners, such as those online. Developing trust and reciprocity is a challenge in peer-to-peer e-commerce where interactions are frequently anonymous and they lack information to assess the trustworthiness of e-vendors. It seems that in case of fully favourable or unfavourable offers, such as hyperfair or unfair ones, people make easily their decision and they don't need other information. Mid-value offers, such as fair ones, support the importance of reputation in e-commerce [50]: with similar offers people could make their decision by considering the reputation of evendors.

Although the results seem promising, they need to be viewed cautiously because of two limitations: the sample size and the gender distribution of the sample. Future studies should include both male population and combine the analyses of eye movements with other process tracing techniques, such as verbal protocol techniques (16).

\section{REFERENCES}

[1] Sanfey AG, Loewenstein G, McClure SM, Cohen JD. Neuroeconomics: cross-currents in research on decision-making. Trends Cogn Sci 2006; 10(3): 108-16.

[2] Von Neumann J, Morgenstern O. Theory of games and economic behavior. Princeton: Princeton university press 1944.

[3] Tversky A, Kahneman D. Judgment under Uncertainty: Heuristics and Biases. Science 1974; 185: 1124-31.

[4] Glimcher PW, Rustichini A. Neuroeconomics: the consilience of brain and decision. Science 2004;15(306): 447-52.

[5] Camerer C, Loewenstein G, Prelec D. Neuroeconomics: how neuroscience can inform economics. J Econ Lit 2005; 43(1): 9-64. 
[6] Posner M, Snyder C. Facilitation and inhibition in the processing of signals. In: Rabbitt PMA, Dornic S, Eds. Attention and Performance. New York: Academic Press 1975; p. 669-82.

[7] Schneider W, Shiffrin RM. Controlled and automatic human information processing: I. Detection, search, and attention. Psychol Rev 1977; 84(1): 1-66.

[8] Goel V, Buchel C, Frith C, Dolan RJ. Dissociation of mechanisms underlying syllogistic reasoning. Neuroimage 2000; 12(5): 504-14.

[9] Kahneman D. A perspective on judgment and choice: mapping bounded rationality. Am Psychol 2003; 58(9): 697-720.

[10] Stanovich KE, West RF. Individual differences in reasoning: Implications for the rationality debate? In: T. Gilovich DG, D. Kahneman, Ed. Heuristics and Biases: The Psychology of Intuitive Judgment New York: Cambridge University Press 2002; p. 421-40.

[11] Sloman SA. Two systems of reasoning. In: Gilovich TaG D, Ed. Heuristics and Biases: The Psychology of Intuitive Judgment. New York: Cambridge University Press 2002; p. 379-96.

[12] Just MA, Carpenter PA. Eye fixations and cognitive processes. Cognitive Psychology 1976; 8: 441-80.

[13] Rayner K. Eye movements in reading and information processing: 20 years of research. Psychol Bull 1998; 124(3): 372-422.

[14] Lohse GL, Johnson EJ. A comparison of two process tracing methods for choice tasks. Organ Behav Hum Dec 1996; 68(1): 2843

[15] Glaholt MG, Wu M, Reingold EM. Predicting preference from fixations. PsychNology J 2009; 7: 141-58.

[16] Glaholt MG, Reingold EM. Eye movement monitoring as a process tracing methodology in decision making research. J Neurosci Psychol Econ 2011; 4: 125-46.

[17] Shimojo S, Simion C, Shimojo E, Scheier C. Gaze bias both reflects and influences preference. Nat Neurosci 2003; 6(12): 131722.

[18] Simion C, Shimojo S. Early interactions between orienting, visual sampling and decision making in facial preference. Vision Res 2006; 46(20): 3331-5.

[19] Simion C, Shimojo S. Interrupting the cascade: orienting contributes to decision making even in the absence of visual stimulation. Percept Psychophys 2007; 69(4): 591-5.

[20] Russo JE, Leclerc F. An eye-fixation analysis of choice processes for consumer nondurables. J Consum Res 1994; 21: 275-90.

[21] Simion C, Shimojo S. Early interactions between orienting, visual sampling and decision making in facial preference. Vision Res 2006; 46(20): 3331-5.

[22] Kunst-Wilson WR, Zajonc RB. Affective discrimination of stimuli that cannot be recognized. Science 1980; 1(207): 557-8.

[23] Moreland RL, Zajonc RB. Is stimulus recognition a necessary condition for the occurrence of exposure effects? J Pers Soc Psychol 1977; 35(4): 191-9.

[24] Moreland RL, Zajonc RB. Exposure effects in person perception: Familiarity, similarity, and attraction. J Exp Soc Psychol 1982;18: 395-415.

[25] Zajonc RB. Attitudinal effects of mere exposure. J Person Soc Psychol 1968; 9(2P2): 1-27.

[26] Güth W, Schmittberger R, Schwarze B. An Experimental analysis of ultimatum bargaining. J Econ Behav Organ 1982; 3(4): 367-88.

[27] Camerer C. Behavioral game theory: experiments in strategic interaction. Princeton, NJ: Princeton University Press 2003.

[28] Bolton GRZ. Anonymity versus punishment in ultimatum bargaining. Games Econ Behav 1995; 10: 95-121.

[29] Thaler RH. Anomalies: The ultimatum game. J Econ Perspect 1988; 2: 195-206
[30] Rabin M. Incorporating Fairness Into Game Theory and Economics. Am Econ Rev 1993; 83: 1281-302.

[31] Fehr E, Schmidt KM. A theory of fairness, competition, and cooperation. Q J Econ 1999; 114: 817-68.

[32] Castelli I, Massaro D, Sanfey AG, Marchetti A. Fairness and intentionality in children's decision-making. Int Rev Econ 2010; 57(3): 269-88.

[33] Marchetti A, Castelli I, Harlé K, Sanfey AG. Expectations and outcome: the role of Proposer features in the Ultimatum Game. J Econ Psychol 2011; 32: 446-9.

[34] Solnick SJ, Schweitzer ME. The Influence of Physical Attractiveness and Gender on Ultimatum Game Decisions. Organ Behav Hum Dec 1999; 79(3): 199-215.

[35] Blount S. When social outcomes are not fair: The effects of causal attributions on preferences. Organ Behav Hum Dec 1995; 63: 13144.

[36] Sanfey AG, Rilling JK, Aronson JA, Nystrom LE, Cohen JD. The neural basis of economic decision-making in the Ultimatum Game. Science 2003; 13(300): 1755-8.

[37] Sutter M. Outcomes versus intentions: On the nature of fair behavior and its development with age. J Econ Psychol 2007; 28: 69-78.

[38] Hoffman E, McCabe K, Smith V. The Impact of Exchange Context on the Activation of Equity in Ultimatum Games. Exp Econ 2000; 3: 5-9.

[39] Marchetti A, Castelli I, Sanfey AG. Teoria della Mente e decisione in ambito economico: un contributo empirico. In: Antonietti A, Balconi M, editors. Mente ed economia Come psicologia e neuroscienze spiegano il comportamento economico. Bologna: Il Mulino 2008; p. 191-207.

[40] Delgado MR, Frank RH, Phelps EA. Perceptions of moral character modulate the neural systems of reward during the trust game. Nat Neurosci 2005; 8(11): 1611-8.

[41] Burnham T, McCabe K, Smith VL. Friend-or-foe intentionality priming in an extensive form trust game. J Econ Behav Organ 2000; 43: 57-73.

[42] Hoffman E, McCabe K, Shachat S, Smith V. Preferences, property rights and anonimity in bairganing games. Games Econ Behav 1994;7: 346-80.

[43] Lapidot-Lefler N, Barak A. Effects of anonymity, invisibility, and lack of eye-contact on toxic online disinhibition. Comput Hum Behav 2012; 28(2): 434-43.

[44] Leder H, Tinio P, Fuchs I, M , Bohrn I. When attractiveness demands longer looks: the effects of situation and gender. Q J Exp Psychol 2010; 63(9): 1858-71.

[45] Cress U, Kimmerle J. Endowment heterogeneity and identifiability in the information-exchange dilemma. Comput Hum Behav 2008; 24: 862-74.

[46] Kimmerle J, Cress U, Hesse F, W. An interactional perspective on group awareness: Alleviating the information-exchange dilemma (for everybody?). Int J Hum Comput Stud 2007; 65: 899-910.

[47] Buss D. Evolutionary psychology: the new science of the mind, 4th ed. Boston: Prentice Hall 2011.

[48] Piazza J, Bering J, M. . Evolutionary cyber-psychology: Applying an evolutionary framework to Internet behavior. Comput Hum Behav 2009; 25: 1258-69.

[49] Kenrick DT, Li NP, Butner J. Dynamical evolutionary psychology: Individual decision rules and emergent social norms. Psychol Rev 2003; 110(1): 3-28.

[50] Xiong L, Liu L. A reputation-based trust model for peer-to-peer ecommerce communities. IEEE Conference on E-Commerce (CEC'03) 2003. 